\title{
Exploration and Practice on Teaching Reform of Thermal Process Control System
}

\author{
Zhang Yuyan* \\ Shen Yang Institute of Engineering \\ Automatic Control Department \\ Shenyang, China \\ zhangyy@sie.edu.cn \\ * Corresponding Author \\ Zhang $\mathrm{Na}$ \\ Shen Yang Institute of Engineering \\ Automatic Control Department \\ Shenyang, China \\ zhangna_sie@163.com
}

\author{
Ma Yang \\ Shen Yang Institute of Engineering \\ Automatic Control Department \\ Shenyang, China \\ mayanghc@163.com \\ Bao Yan \\ Shen Yang Institute of Engineering \\ Automatic Control Department \\ Shenyang, China \\ baoyan@sie.edu.cn
}

\begin{abstract}
The thermal process control system is a comprehensive course, which aims at thermal production process and uses conventional instrumentation as the tool on the basis of control theory, making it a professional core course in automation specialty and related professions. Studying this course can train skilled personnel for thermal power plant and related majors, make students understand the development of thermal process control technology. In this paper, the status quo and some problems are analyzed. Course innovation teaching reform and experience have been discussed from the teaching content, teaching method, teaching means and practical teaching. Through the teaching reform and practice of the thermal process control system, students can understand and master each part of knowledge well, and have a new understanding of the course related basic theory, which also cultivates students' engineering concept and ability. Practice shows that the reform has achieved good effect in the course of teaching.
\end{abstract}

Keywords-Thermal process control system; Comprehensive course; Practical teaching; Innovation; Teaching reform

\section{INTRODUCTION}

The thermal process control system is a comprehensive course[1], which aims at thermal production process and uses conventional instrumentation as the tool on the basis of control theory, making it a professional core course in automation specialty and related professions. This course features a fast update teaching content, a high level of expertise and practicalness, and theoretical teaching and experimental teaching share the same importance. It involves in a wide range of the basic theory and knowledge, which are comprehensive knowledge, such as computer technology, detection technology, distributed control system and instrument and so on. Through the learning of this course, skilled talents are trained for the power plant and related professions, and students are aware of the development of thermal process control technology and they can master the basic knowledge and engineering methods of the thermal process control system analysis, design and running. This course has played an important role in supporting and promoting the cultivation of students' vocational ability, integrating theory with practice, and lays a solid foundation for students engaging in related work in the future.

With the rapid development of the computer control technology, detection technology and modern control technology[2-3], an important branch of process control system technology of automation technology also develops, so that application in electric power, metallurgy, light industry and other industries is becoming more and more widely. Thermal process control system course must reform teaching content and concept, as well, improve the methods and means with the appearance of new technology and application. This article, combined with the practice of the construction of thermal process control system in the school outstanding curriculum, analyzes the current situation of theory teaching and practice teaching of the course, and explores a few problems of the curriculum system construction and practice teaching design, teaching method reform and innovation, so as to cultivate automation professionals with a solid professional foundation and innovative thinking as well as engineering practice ability.

\section{THE ANALYSIS OF PRESENT SITUATION OF THERMAL PROCESS CONTROL SYSTEM CURRICULUM TEACHING}

The thermal process control system is a more comprehensive course, involving many specialized basic courses[4-5]. The scheme of the design, analysis and specific implementation of the control system needs the understanding of the principle of control system as well as the actual production process background, and knowledge of automation instrument and engineering application of computer technology. So if students do not master in the learning process, they are forced to learn the related basic knowledge which they do not understand enough in depth again and again, which makes students lose interests in learning. Therefore, in the teaching, the problems of how 
to combine the teaching with related priory knowledge of the course content should be solved. And mastery will be achieved through a comprehensive multi-disciplinary knowledge and best link up each part of the knowledge, so as to stimulate students' interest in learning, to achieve satisfactory teaching effect.

In the current teaching process, teachers are treated as the main body with knowledge as the center. They follow a fixed pattern of asking questions, reviewing, introducing, teaching, discussing and summary as well as homework. The teaching interaction only exist ask-andanswer between teachers and student. In the one-way communication, students lack the ability of autonomous learning. Although teachers spend a lot of energy in class, the teaching effect is not very ideal. So, based on optimizing the teaching content, improving teaching methods and enriching teaching method is the main content of the course teaching reform, which brings benefits to cultivating students' research, analysis and problem solving skills[6]. And a diversity of teaching methods can attract students' attention, improving their learning interest.

\section{THE REFORM OF THE TEACHING CONTENT AND METHOD OF THERMAL PROCESS CONTROL SYSTEM}

\section{A. The reform of the teaching content}

The curriculum nature of thermal process control system is to realize the control of the process industry system, with various kinds of instrument as tools, based on control theory. Teaching content mainly includes: the key technology of various components of the process control system, such as detection instrument, control instrument, actuator and the mathematical model generating thermal object, PID control rule, and simple control system design and parameter setting, complex structure and design of the control system, advanced process control technology, computer control system and other new type control system and process control system.

In the organization of the teaching content, in order to solve the problem that students lack overall understanding of thermal process control system, several examples of power plant production process are found to introduce in the overview section of the course, letting the student have a perceptual knowledge to the actual process control system in the initial stage of the course, forming a basic understanding of the components of the thermal process control system. And then in the subsequent chapters of teaching, interpret around the application examples. At last, the practice teaching link makes students do the system design on their own. Considering the continuous development of process control technology feature, in the teaching, teachers are required not to be limited to the contents of the textbooks, but add and remove trade-offs to the teaching material content, update teaching content, blend the latest technology and information in teaching, and introduce them to students in time. At the same time, for the knowledge which has been out of date, there are no requirements. When teaching actuators, for example, the author do not only systematically introduce the electric actuators and pneumatic actuators used in all kinds of industries, but also introduces the current popular inverter technology and its application.

\section{B. The reform of the teaching methods}

On the foundation of optimization of teaching contents, the reform of the teaching method is the main content of the curriculum reform. At present, the teaching of this course is mainly composed of classroom teaching, and whether classroom teaching effect is good or bad, directly affects the quality of students learning. Therefore, in the process of classroom teaching, the teacher is taken as the leader and student as the main body, transforming from one-way transmission of knowledge teaching to twoway communication and the research-oriented teaching. For the course to be vivid and to stimulate students' initiative and interest, classes are all made of the multimedia courseware combined with MATLAB simulation way of teaching[7-9]. Stimulate theory of learned knowledge timely with MATLAB, strengthening the students' understanding the course content. And, when using MATLAB/Simulink[10] to interpret control system at the same time, the use of the MATLAB/Simulink simulation software can be introduced to students, for the subsequent practice teaching link in the curriculum design. In addition, the course is added with a large number of examples of engineering application, which will introduce a typical thermal process production equipment course, introducing the technological characteristics, dynamic characteristics analysis. Leave the research-oriented curriculum design assignment; require students to design their own actual controlled object oriented process control system. For example, simulate and research for large delay object with the MATLAB software, as shown in Figure 1.

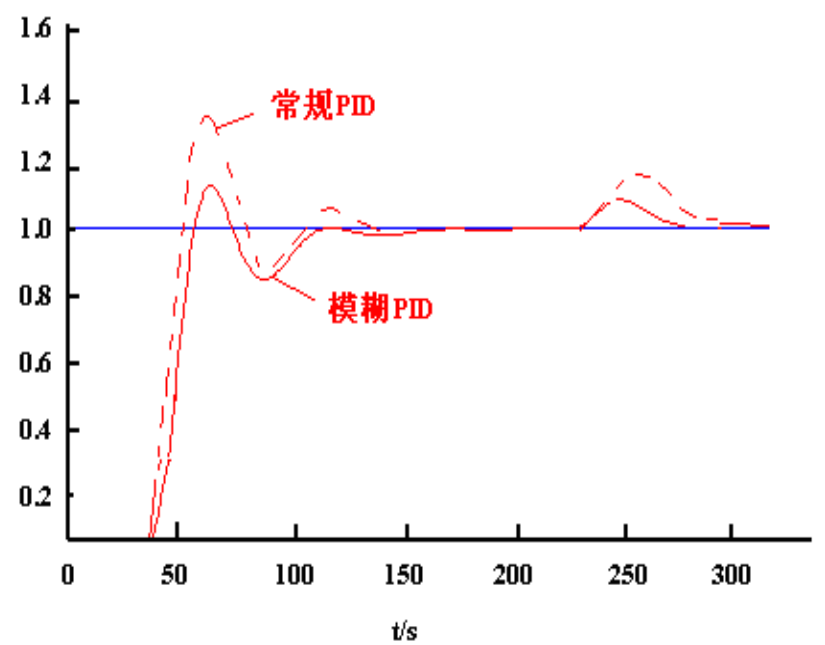

Fig. 1 Control system output curve

\section{The reform of teaching methods}

At present, the multimedia technology has been introduced as an auxiliary means into teaching. In the thermal process control system teaching system, there are more SAMA legends, so COM automation technology is used. In the multimedia teaching courseware, various typical power plant production process control and all kinds of algorithm of MATLAB/Simulink are shown to students, which makes the students not have to enter the production site. They can understand the whole process of thermal production in a multi-angle way, which deepens students' 
understanding of the concepts of instrument working principle; and at the same time, in the classroom, simulation demonstration with inducting control system design shall be done, and the comparison between all kinds of control system structure and the control effect of control algorithm shall be carried out, the parameters of the control algorithm shall be manually adjusted, and the parameters of control effect shall be analyzed and compared, enhance the students' perceptual knowledge, improving the classroom effect of science and technology teaching experiment. In addition, in order to avoid that students



Fig 2. Configuration and operation interface diagram of double tank liquid level system

\section{The reform of practice teaching}

The thermal process control system is a practical and strong comprehension professional course. To adapt to the social demand for talents, cultivating creative and interdisciplinary talents has become the main goal of most colleges and universities. In order to achieve this goal, the practice circle must be strengthened under the premise of emphasizing theory teaching. Practice teaching is an important part of the course teaching. Due to the limitation of the teaching content and teaching hours, teaching is carried out in the form of a variety of practical teaching mode of combination, to cultivate students' ability to use learning theory knowledge ability to solve practical production problems. In the practice teaching link, add curriculum design with design ability and innovative ability. Course design is the design and implementation of a boiler control system to control each controlled indexes in the process of production of boiler. According to multiple index and control algorithm, it can be divided into several subjects. Put $3 \sim 5$ students in a group and have difficulty extracting key points from the very large amount of information in multimedia course ware, combine classroom blackboard writing and multimedia, appropriately adding some blackboard writing in the process of teaching to clarify the key points, but also helping to attract the attention of students. The control system of the double tank liquid level control system is shown in Figure 2, the system can express the change of the liquid level of the double tank vividly. 
motivation, strengthen their understanding and mastering of knowledge, cultivate students' comprehensive ability of applying knowledge to solve actual problem becomes the key issue in the experiment teaching to solve.

Process control laboratory is equipped with advanced laboratory apparatus (two sets THKGK - type 1 process control experimental device, manufactured by Tianhuang Corp. ), which means it's able to carry out all the thermal process control system experiments. Having optimized integration of experimental contents, adopt method of combining confirmatory experiments and comprehensive design experiment, paying attention to transforming some forefront automatic technology into the students' experiment content. As well, take reform experiment project and open experiment teaching. These two methods have been conducted some kind of reform, which has obtained the certain effect.

\section{CONCLUSIONS}

This course is an engineering practical subject. Only through hands-on practice can the knowledge be really mastered. Through the teaching reform and practice of the thermal process control system, students better understand and master each part of knowledge and have a new understanding of the course related basic theory [6], which also cultivates students' the engineering concept and ability. Through the reform in experiment circle, students can apply knowledge to engineering practice, improving their beginning ability, training the ability to analyze and to solve problems. Due to the reform of this course, students acquire some foundations of the control system and they have mastered the basic design process, which, to a certain extent, will help them to better complete the following graduation design.

\section{ACKNOWLEDGMENT}

This work was supported in part by Liaoning Province Education Science "Twelfth Five Year Plan" project under Grant No.JG14DB292, JG15DB289 and JG15DB301, Course construction project of quality resources sharing in Liaoning Province.

\section{REFERENCES}

[1] JIN Yi-hui, Process Control [M].Beijing: Tsinghua University press, 1993

[2] LIU Shan, ZHEGN Wen-feng, Teaching Reform of Process Control System Course $[\mathrm{J}]$. Experiment Science \& Technology, 2013:70-72.

[3] YANG Jia, XU Qiang, Lei Shao-lan, Course teaching and experiment reform of process control system[J], CEPE,2010:125126.

[4] SUN Jing-gao, LUO Jian-xu, LIU Man-dan, Exploration and practice on innovation teaching and construction of the national excellent course in process control engineering, $[\mathrm{J}]$, Higher Education in Chemical Engineering, 2012:15-16

[5] LI Tian-Hua, JL Hou, GY Shi, Discussion on teaching reform of process control system [J]. Laboratory Science, 2012:43-45.

[6] LI Tian-Hua, GY Shi, JL Hou, Reforming Process Control System Teaching to Improve Students' Application Ability [J]. Research \& Exploration in Laboratory, 2013:111-113

[7] CM Ong, Dynamic Simulations of Electric Machinery: Using MATLAB/SIMULINK[J]. Prentice Hall, 2015

[8] A Gilat, MATLAB : an introduction with applications [J]. J. Wiley \& Sons, 2015, 16(2):115

[9] P O'Shea, Digital Signal Processing - An Introduction with MATLAB and Applications | Springer [J]. Springer-Verlag Berlin Heidelberg,2011

[10] LIU Jin-kun, Advanced PID control and MATLAB simulation [M].Beijing: Electronics Industry Press, 2003:68 